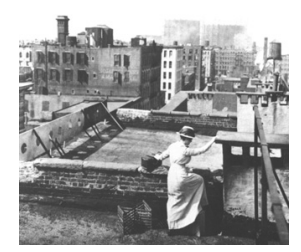

\title{
O agente comunitário de saúde: algumas reflexões
}

The community healthcare agent: a few thoughts

Mário Roberto Dal Poz ${ }^{1}$

O texto de Silva \& Dalmaso, ao examinar aspectos da competência e das atividades do cotidiano dos agentes comunitários de saúde, alimenta $e$ estimula o debate sobre certos desafios para sua formação.

Tradicionalmente, agentes comunitários de saúde têm assumido importantes tarefas no cuidado de saúde, em diferentes sistemas e contextos.

A atenção ao parto tem sido uma função tradicional e importante de parteiras tradicionais (comunitárias ou empíricas). Diferentes países utilizam membros da comunidade para o desenvolvimento de outras funções de atenção à saúde, como primeiros socorros e vigilância à saúde. Em países em desenvolvimento, há muitos anos utiliza-se o treinamento de membros da comunidade como estratégia para aumentar a qualidade da atenção (Nair et al., 2001).

Um dos desafios e tendências atuais é a introdução de novos papéis e responsabilidades para esse grupo junto ao sistema de saúde. A expansão do papel das parteiras tradicionais em Zimbabwe e o treinamento de agentes comunitários de saúde no Brasil para desenvolver cuidado clínico são exemplos dessa tendência.

Sparks (1990), num estudo com parteiras tradicionais (TBAs) em Zimbabwe, mostrou que seu papel vem mudando gradualmente, a partir da

${ }^{1}$ Médico, Coordenador de Recursos Humanos para a Saúde, Departamento de Provisão de Serviço de Saúde, Organização Mundial de Saúde. <dalpozm@who.int> 
decisão das mulheres de usarem clínicas para dar à luz seus bebês.

Parteiras tradicionais representam um recurso importante no cuidado básico de saúde em muitos países em desenvolvimento. Cursos de formação ou capacitação para atualizar ou aumentar as habilidades das parteiras são comuns e encorajadas por diferentes agências. O foco da formação é a realização de um parto seguro e o reconhecimento de que a gravidez de alto-risco necessita ser referenciada para uma unidade de saúde mais especializada. Atualmente, os programas de formação introduzem outras habilidades para aumentar a participação desses agentes de saúde em atividades primárias de cuidado de saúde, mais na linha de promoção de saúde e prevenção de problemas específicos nos grupos populacionais das mães e das crianças.

A experiência do Brasil também ilustra este ponto. O Programa de Agentes Comunitários de Saúde, PACS, foi formulado tendo como objetivo central contribuir para a redução da mortalidade infantil e mortalidade materna, principalmente nas regiões Norte e Nordeste, por meio de uma extensão de cobertura dos serviços de saúde para as áreas mais pobres $e$ desvalidas. Porém, a partir da experiência acumulada pelo estado do Ceará com o programa de agentes comunitários, ali implantado, houve a percepção, pelo próprio Ministério da Saúde, de que os agentes poderiam também ser peça importante para a organização do Serviço Básico de Saúde no município.

A partir de uma formação básica inicial para ações baseadas em vigilância de saúde, os agentes comunitários visitam as famílias das comunidades $e$ proporcionam cuidado a doenças comuns, imunização, medicação e educação de saúde. Esta iniciativa, que se tornou o modelo seguido pelo Ministério da Saúde, operado em diversos níveis, pelos Estados e municípios brasileiros, tem apresentado resultados que o fazem um dos esforços mais eficientes de saúde no mundo. Desde sua implementação tem havido um declínio significativo em mortalidade infantil, um aumento de níveis de imunização, avaliação de necessidades e recursos e uma intervenção profissional mais rápida quando necessária (Svitone et al., 2000).

Em geral, em áreas rurais do sul da África, o papel do pessoal de enfermagem e outros trabalhadores de saúde é crucial para estender a cobertura dos cuidados de saúde. Reconhece-se que este pessoal, em muitos casos, tem o âmbito de seu trabalho severamente limitado pela falta de formação adequada e reconhecimento social. A enfermeira é normalmente a única profissional disponível na área reduzindo, assim, as alternativas para diagnosticar e tratar pacientes.

No Brasil, duas questões tomaram relevância no processo de implantação do PACS: a escolha do agente (envolvendo questões como processo seletivo, capacitação, avaliação etc.) e as condições institucionais da gestão da saúde no nível local (grau de participação dos usuários - formação dos Conselhos de Saúde; grau de autonomia da gestão financeira; recursos humanos disponíveis; capacidade instalada disponível etc.).

Pelo fato de o programa de agentes comunitários ter tomado essa forma, ele não constituiu apenas mais um programa vertical do Ministério da Saúde (uma ação paralela ao sistema de saúde) tendo sido, também, um braço 
auxiliar do sistema de saúde na organização dos sistemas locais de saúde (Dal Poz \& Viana, 1999).

Isto porque, no momento em que a adesão do município ao PACS exigiu e exige certos requisitos, como o funcionamento dos Conselhos Municipais de Saúde, a existência de uma unidade básica de referência do programa, a disponibilidade de um profissional de nível superior na supervisão e no auxílio às ações de saúde, a existência de Fundo Municipal de Saúde para receber os recursos do programa, este se tornou, sobretudo, um instrumento de (re)organização dos modelos locais de saúde.

Ressalte-se, entretanto, que não foi apenas por ter definido essa estratégia de implantação que fez do programa um instrumento de (re)organização do sistema de saúde, mas também pelo grau de articulação que este desenvolveu com os diferentes níveis (estadual e municipal), além do papel desempenhado pelos atores participantes do processo de implementação do programa (agentes e comunidade) (Dal Poz E Viana, 1999).

Referências

DAL POZ, M.R., VIANA, A.L. Estudo sobre o processo de reforma em saúde no Brasil. In: MARTINIC, S., AEDO, C., CORVALAN, J. (org.) Reformas en Educacion y Salud en America Latina y el Caribe. Santiago do Chile: Centro de Investigación y Desarrollo de la Educación - CIDE, 1999. p.187-217.

NAIR, V.M., THANKAPPAN, K.R., SARMA, P.S., VASAN, R.S. Changing roles of grass-root level workers in Kerala, India. Health Policy Plan., v.16, n.2, p.171.

SPARKS, B. T. A descriptive study of the changing roles and practices of traditional birth attendants in Zimbabwe. J. Nurse-Midwifery, v. 35, n.3, May/June, 1990.

SVITONE, E. C., GARFIELD, R., VASCONCELOS, M. I., CRAVEIRO, V. A. Primary health care lessons from the Northeast of Brazil: the Agentes de Saúde Program. Pan. Am. J. Public Heath, v.7, n.5, p.293-302, 2000.
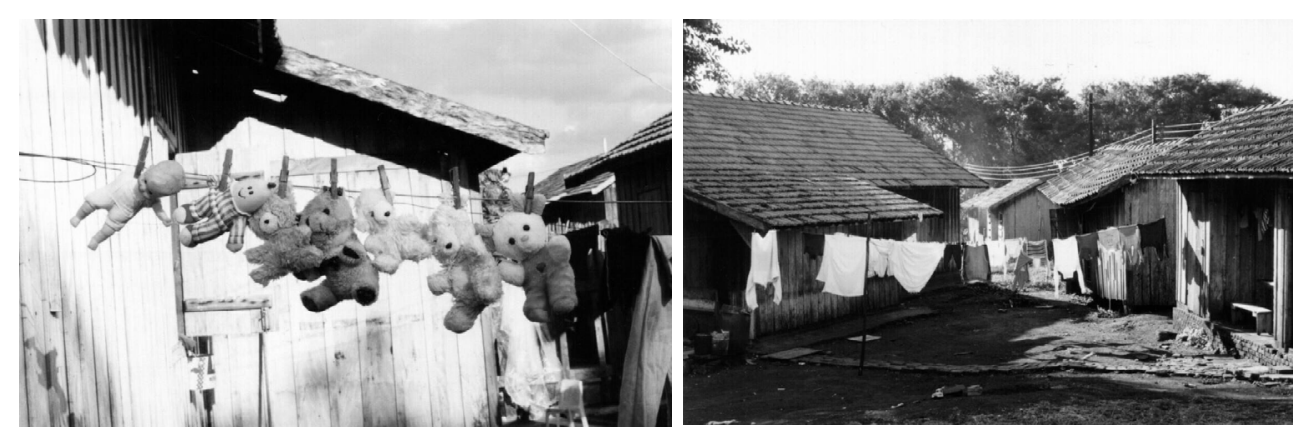

TRAJANO SARDENBERG, 2001 